\title{
Effects of Variable and Constant Temperatures on the Embryonic Development and Survival of a New Grape Pest, Xylotrechus arvicola (Coleoptera: Cerambycidae)
}

\author{
Author(s) :E. García-Ruiz, V. Marco and I. Pérez-Moreno
}

Source: Environmental Entomology, 40(4):939-947. 2011.

Published By: Entomological Society of America

DOI: http://dx.doi.org/10.1603/EN11080

URL: http://www.bioone.org/doi/full/10.1603/EN11080

BioOne (www.bioone.org) is a nonprofit, online aggregation of core research in the biological, ecological, and environmental sciences. BioOne provides a sustainable online platform for over 170 journals and books published by nonprofit societies, associations, museums, institutions, and presses.

Your use of this PDF, the BioOne Web site, and all posted and associated content indicates your acceptance of BioOne's Terms of Use, available at www.bioone.org/page/terms_of_use.

Usage of BioOne content is strictly limited to personal, educational, and non-commercial use. Commercial inquiries or rights and permissions requests should be directed to the individual publisher as copyright holder. 


\title{
Effects of Variable and Constant Temperatures on the Embryonic Development and Survival of a New Grape Pest, Xylotrechus arvicola (Coleoptera: Cerambycidae)
}

\author{
E. GARCÍA-RUIZ, ${ }^{1}$ V. MARCO, AND I. PÉREZ-MORENO \\ Departamento de Agricultura y Alimentación, Complejo Científico - Tecnológico, ICVV (Universidad de La \\ Rioja - Gobierno de la Rioja - CSIC), Madre de Dios 51, 26006 Logroño, La Rioja, Spain
}

Environ. Entomol. 40(4): 939-947 (2011); DOI: 10.1603/EN11080

\begin{abstract}
Xylotrechus arvicola Olivier (Coleoptera: Cerambycidae) has become a new expanding pest in grape (Vitis spp.) crops. To better improve control tactics, the consequences of 11 constant $\left(12,15,18,21,24,27,30,32,34,35\right.$ and $\left.36^{\circ} \mathrm{C}\right)$ and nine variable temperatures (with equal mean temperatures at each of the nine constant rates ranging from 15 to $35^{\circ} \mathrm{C}$ ) on survival and embryonic development were studied. The eggs were able to complete development at constant temperatures between 15 and $35^{\circ} \mathrm{C}$, with mortality rates at the extremes of the range of two and $81.5 \%$, respectively. Using variable temperatures a mortality rate of $38.9 \%$ at a mean temperature of $15^{\circ} \mathrm{C}$ and $99 \%$ at $35^{\circ} \mathrm{C}$ was observed. The range of time for embryonic development was $29.5 \mathrm{~d}$ at $15^{\circ} \mathrm{C}$ to $6 \mathrm{~d}$ at $32^{\circ} \mathrm{C}$ at constant temperatures, and from $29.6 \mathrm{~d}$ at $15^{\circ} \mathrm{C}$ to $7.2 \mathrm{~d}$ at $32^{\circ} \mathrm{C}$ at variable temperatures. The goodness-of-fit of different development models was evaluated for the relationship between the development rate and temperature. The models that gave the best fit were the Logan type III for constant temperatures and the Brière for variable temperatures. Optimum temperatures were estimated to be from 31.7 to $32.9^{\circ} \mathrm{C}$. The models that best described embryo development under natural field conditions were the Logan type III model for constant temperatures (98.7\% adjustment) and the Lactin model for variable temperatures (99.2\% adjustment). Nonlinear models predicted faster development at constant temperatures and slower development at variable ones when compared with real field development, whereas the linear model always predicted faster development than what actually took place.
\end{abstract}

KEY WORDS Xylotrechus arvicola, developmental rate, variable temperature, thermal threshold, field validation

The grape is one of the crops that has benefited most in the last few years from the introduction of more environmentally sound pest control strategies. Most of them are based on an extensive knowledge of the biology and ecology of the pest species. Thus, to continue this trend, it is of vital importance to generate this information for species that have become pests in recent years, such as Xylotrechus arvicola Olivier (Coleoptera: Cerambycidae), a xylophagous species inhabiting dead wood and decaying trees in many parts of Europe, West Asia and North Africa (Villiers 1978). In the 1990s it was found in vineyards in La Rioja (Spain) damaging the grape stem and branches (Ocete and Del Tío 1996). Since then, it has rapidly expanded throughout this and other important wine regions, such as Castilla-La Mancha (Rodríguez et al. 1997), Castilla-León (Moreno 2005) and Navarre (Ocete et al. 2002) and endangers one of the key crops in Spain covering >1.3 million cultivated hectares.

${ }^{1}$ Corresponding author, e-mail: esteban.garcia@inia.es
The harm caused by larvae-digging galleries diminishes the plant's capacity to transport sap by reducing the vascular area and allowing fungal spread, resulting in less productive berries that degrade wine quality. To the best of our knowledge, it has not been recorded as a pest in any other part of the world, but this species could threaten other wine regions inside, or even beyond, its current area of distribution.

Currently, growers do not have efficient control tools against X. arvicola. The available preventive prophylactic measures are ineffective because little is known about the biology of this pest. Adults are present in the field between the end of March and the end of July, with higher population levels at the end of May. Eggs are laid in the cracks of bark, and newly emerged larvae rapidly penetrate the plant. The number of larval instars is not yet known, but may be variable, as occurs with other species of the same family (Adachi 1988). Low temperature during the last larval instar's development induces a diapause. After more than a 1-yr larval growing period, a broader gallery connected to the outside is excavated where 
larvae molt to pupae. Adults emerge between 20 and 30 d later. Therefore, four developmental stages can occur simultaneously in the field between April and June (Moreno 2005). Egg-to-adult development in the field lasts 2 yr.

At the time of establishing $X$. arvicola management strategies, it is of great importance to generate sufficient basic knowledge about the pest biology and behavior and to focus the control actions on the most exposed developmental stages, in this case, the egg, adult and neonate larvae, as the other stages develop inside of the wood. Predicting the seasonal occurrence of these different developmental stages requires an understanding of insect development, with the temperature being one of the main factors involved. A variety of mathematical models that describe development rates (proportion of developmental stage completed in a day) as a function of temperature have been formulated (Wagner et al. 1984). These functions range from the classical linear degree-day model to more complex nonlinear models (Sharpe and DeMichele 1977, Hilbert and Logan 1983, Lactin et al. 1995, Brière et al. 1999), which differ in parameter number, complexity, and basic assumptions about temperature effects on upper and lower limits.

Beck (1983) stated that arthropod development cannot be based solely on constant temperatures, because in natural conditions, the insects are exposed to frequent temperature fluctuations, and the influence on the development can be different than that derived from exposure to constant temperatures. The greater the temperature fluctuation around a constant mean, the bigger the difference, because of the nonlinearity of development, or Kaufmann effect (Worner 1992). It is not the duration of the thermal treatment but the change in temperature that causes increases or decreases in the developmental rate compared with that at constant temperatures (Behrens et al. 1983). Some authors have already described greater developmental rates for the higher temperatures and lesser for the lower temperatures than those obtained with the constant temperatures corresponding to the same mean (Ratte 1985, Hagstrum and Milliken 1991, Mironidis and Savopoulou-Soultani 2008).

Because of its recent status as a pest, the development of $X$. arvicola has not been investigated yet. Although the effects of temperature on the development of many coleopteran species have been extensively studied, mainly on the Curculionidae (Marco et al. 1997, Toapanta et al. 2005) and Chrysomelidae (Weston and Díaz 2005) families, these kinds of studies are much scarcer in cerambycid species (Keena 2006).

Given that one of the most vulnerable developmental stages of $X$. arvicola is the neonate larva, it becomes critical to evaluate the effect of temperature on embryonic development to predict egg hatch in the field. Therefore, the ability of the linear model and the three nonlinear models (Logan type III, Lactin and Brière) in predicting the embryonic development of this species under constant and fluctuating temperatures was evaluated and the models were validated under real field conditions.

\section{Materials and Methods}

Insects. To obtain adults of $X$. arvicola, infested grape wood from different commercial vineyards located in Cigales (Valladolid, Spain) were brought to the laboratory in 2005 and kept in 55 - by $40-$ by $35-\mathrm{cm}$ (length-width-depth) plastic containers at $24 \pm 1{ }^{\circ} \mathrm{C}$, $60 \pm 5 \% \mathrm{RH}$, and a photoperiod of 16:8 (L:D) h. Newly emerged adults $(<24 \mathrm{~h})$ were sexed using the color of the femurs (Moreno 2005) and then were paired (one male and one female), in 12-cm-diameter plastic cylindrical cages with a perforated lid covered with a fine mesh. Cage bottoms were covered with filter paper. Cotton impregnated with a $10 \%$ honey solution was provided as a food source and a laying substrate consisting of a 13- by 4-cm (length-breadth) rolled paper also was added to the cage. These adult mating cages were maintained in a growth chamber (Sanyo MLR$350 \mathrm{H}$, Sanyo, Japan) at $24 \pm 1^{\circ} \mathrm{C}, 60 \pm 5 \% \mathrm{RH}$, and a photoperiod of 16:8 (L:D) h. If a male died another was added to the cage to allow the female to continue laying eggs.

Laboratory Bioassays. The eggs required for each experimental temperature were obtained by checking the laying substrates of the mating cages described above, daily. Once counted, the egg batches were placed separately in 55-mm-diameter, 14-mm-deep petri dishes that were covered with aluminum foil to ensure hatching in complete darkness. The petri dishes with eggs of the different females laid in the same day $(<24 \mathrm{~h})$ were then introduced in a growth chamber with programmable temperature.

The duration of the embryonic development and survivorship were determined at 11 constant temperatures $\left(12,15,18,21,24,27,30,32,34,35\right.$ and $\left.36^{\circ} \mathrm{C}\right)$. With the aim of establishing the possible differences in mean developmental time between constant and variable temperatures, nine type-days were constructed where the temperature fluctuated each hour but with the same mean as at each of the nine constant temperatures between 15 and $35^{\circ} \mathrm{C}$, and with minimum and maximum temperature maintained between 12 and $36.5^{\circ} \mathrm{C}$ (Fig. 1).

The variable temperature limits of 12 and $36.5^{\circ} \mathrm{C}$ were established based on the highest lower threshold and the lowest upper threshold calculated respectively by the constant temperature models. The variable temperature curves were constructed according to a daily temperature oscillation (colder in the early morning and warmer in the afternoon) with different mean temperatures and transferred to the growth chamber with the help of the OMRON Multisystem 3.0 program, which controlled the temperature changes established by users.

For each temperature regime the number of eggs used was between 68 and 186 eggs, depending on their availability each day. The eggs were observed twice a day, and hatching and mortality were recorded. 


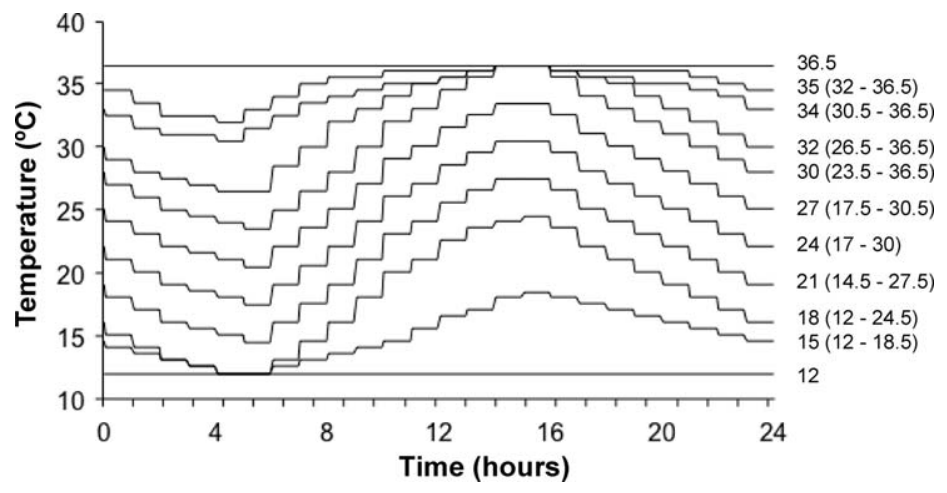

Fig. 1. Type-days constructed for the embryonic temperature-dependent development monitoring at variable temperatures. Note that the right hand column represents "Mean Temperature (Range)".

Mathematical models. The relationship between temperature $(T)$ and developmental rate $(r=1 / \mathrm{d})$, under constant and alternating temperatures was determined by both linear and nonlinear regression models. The empirical nonlinear models were selected because these models are better quantitatively at both high and low temperatures than the traditional degree-day model, and unlike other nonlinear models, these can predict the lower (LT) and upper (UT) temperature threshold for development.

Linear Model. The relationship between $T$ and $r$ was predicted by a regression analysis where $r=a+b T$; $a$ and $b$ were estimated by least-squares regression. The lower developmental threshold $\left(T_{0}\right)$ and the degree-day requirements $(D D)$ were estimated by the equations $T_{0}=-a / b$ and $D D=1 / b$.

Logan Type III model. The mathematical expression of this model is a combination of two functions (Hilbert and Logan 1983). The first function (representing the ascending rate of development with the increasing temperatures) is sigmoid. The second function, developed by Logan et al. (1976), represents the descending portion of developmental rate with increasing temperatures. The expression of the model is:

$r(T)=\psi\left(\left(\left(T-T_{b}\right)^{2} /\left(\left(T-T_{b}\right)^{2}+D^{2}\right)\right)\right.$

$$
\left.-\mathrm{e}^{-((T m-(T-T b)) / \Delta T)}\right),
$$

where $T$ is the temperature; $r(T)$ is the developmental rate at $T$ temperature; $T_{b}$ is the base temperature (for temperatures below $T_{b}$, the rate of development presumably equals 0$) ; T_{m}$ is the lethal maximum temperature threshold $\left({ }^{\circ} \mathrm{C}\right.$ above $\left.T_{b}\right) ; \Delta T$ is the width of the high-temperature boundary area; and $\psi$ y $D$ are empirical constants.

Lactin Model. Lactin et al. (1995) modified the nonlinear model proposed by Logan et al. (1976) to obtain another one, which could estimate the upper temperature threshold. To do this they suppressed the $\psi$ parameter and introduced a new one $(\lambda)$ that permits this estimation,

$$
r(T)=\mathrm{e}^{\rho T}-\mathrm{e}^{(\rho \operatorname{Tmax}-(\operatorname{Tmax}-T) / \Delta)}+\lambda
$$

where $T$ is the temperature; $r(T)$ is the developmental rate at $T$ temperature; $T_{\max }$ is the supraoptimal tem- perature at which $r(T)=\lambda ; \Delta$ is the range of temperature between $T_{\max }$ and the temperature at which $r(T)$ is maximum; $\rho$ describes the acceleration of the function from the LT to optimal temperature and $\lambda$ is a parameter that allows the curve to intersect the abscissa at suboptimal temperatures, making possible the estimation of the lower developmental threshold (LT). This parameter represents the asymptote to which the function tends at low temperatures.

Brière Model. With the objective of obtaining a more simplified developmental model, Brière et al. (1999) developed a model with only three parameters whose expression is:

$$
r(T)=a T\left(T-T_{0}\right)\left(T_{L}-T\right)^{1 / 2} \text { for } T_{0}<T<T_{L}
$$

where $T$ is the temperature; $r(T)$ is the developmental rate at $T$ temperature with a value of 0 for temperatures $T<T_{0}$ and $T>T_{L} ; T_{0}$ is the lower developmental threshold; $T_{L}$ is the upper developmental threshold and $a$ an empirical constant.

Statistical Analyses. The effect of temperature on developmental time was determined by using PROC GLM and PROC LSMEANS was used for the least square mean comparisons (SAS Institute 2003). Survival percentages between temperature regimes were compared using the $\chi^{2}$ test (Sokal and Rohlf 1995).

The fit of both the linear and nonlinear models to the developmental rate and the estimation of the different associated parameter values were made with the help of the Tablecurve 2D program (Jandel Scientific 1994). Initial parameter estimation for the nonlinear Logan type III and Lactin models was made following the suggestions of Logan (1988).

Field Validation. To validate the models estimated in the laboratory, field measurements of embryonic development were made in an experimental vineyard situated at the University of La Rioja in Logroño (Spain) during March of 2006. One hundred fifty recently laid eggs kept inside petri dishes covered with aluminum foil were used. The petri dishes containing the separated egg batches were placed inside of a delta trap kept on the ground, to protect it against the solar radiation and rain. A Datalogger Testostor 175 was put beside the dishes allowing the capture of the mean temperature at half hour intervals. Field temperature 
Table 1. Percentage of mortality and mean developmental time ( \pm SE) of $X$. arvicola eggs at constant and variable temperatures

\begin{tabular}{|c|c|c|c|c|c|c|c|}
\hline \multicolumn{2}{|c|}{ Temp $\left({ }^{\circ} \mathrm{C}\right)$} & \multicolumn{2}{|c|}{$\mathrm{N}$} & \multicolumn{2}{|c|}{$\%$ Mortality } & \multicolumn{2}{|c|}{ Developmental time $(\mathrm{d} \pm \mathrm{SD})^{a}$} \\
\hline Constant & Variable $^{b}$ & Constant & Variable & Constant & Variable & Constant & Variable \\
\hline 12 & - & 106 & - & 100 & - & - & - \\
\hline 15 & $15(12-18.5)$ & 101 & 113 & 1.98 & 38.94 & $29.48 \pm 0.07 \mathrm{a}$ & $29.60 \pm 0.32 \mathrm{a}$ \\
\hline 18 & $18(12-24.5)$ & 114 & 155 & 2.63 & 6.45 & $17.52 \pm 0.05 \mathrm{a}$ & $16.04 \pm 0.04 b$ \\
\hline 21 & $21(14.5-27.5)$ & 107 & 148 & 14.95 & 33.78 & $10.30 \pm 0.07 \mathrm{a}$ & $11.48 \pm 0.08 b$ \\
\hline 24 & $24(17-30)$ & 115 & 184 & 26.96 & 8.70 & $8.02 \pm 0.02 \mathrm{a}$ & $10.61 \pm 0.04 b$ \\
\hline 27 & $27(17.5-30.5)$ & 77 & 186 & 64.93 & 13.44 & $7.00 \pm 0.00 \mathrm{a}$ & $7.56 \pm 0.04 \mathrm{~b}$ \\
\hline 30 & $30(23.5-36.5)$ & 106 & 150 & 29.25 & 47.33 & $6.95 \pm 0.03 a$ & $7.32 \pm 0.07 \mathrm{~b}$ \\
\hline 32 & $32(26.5-36.5)$ & 68 & 96 & 54.41 & 75.00 & $6.03 \pm 0.09 a$ & $7.25 \pm 0.09 \mathrm{~b}$ \\
\hline 34 & $34(30.5-36.5)$ & 144 & 128 & 71.53 & 87.50 & $6.41 \pm 0.09 \mathrm{a}$ & $7.31 \pm 0.15 b$ \\
\hline 35 & $35(32-36.5)$ & 178 & 103 & 81.46 & 99.03 & $7.48 \pm 0.12 \mathrm{a}$ & $8.00 \mathrm{a}$ \\
\hline 36 & - & 90 & - & 100 & - & - & - \\
\hline
\end{tabular}

${ }^{a}$ Different letters in the same row show significant differences $(P<0.05$, LSMEANS test).

${ }^{b}$ In brackets the maximal and minimal temp values of the cycle.

during the whole process varied between 8.2 and $35.9^{\circ} \mathrm{C}$, being colder between 4 and $7 \mathrm{~h}$ am and warmer between 14 and $17 \mathrm{~h}$ pm every day. An integration of the increments in development each 30-min intervals within the lower and upper developmental temperature limits given by each model was used. Each day, the number of hatched eggs and mortality was recorded.

\section{Results}

Survival and Development. Eggs of $X$. arvicola were capable of complete development at constant and variable temperatures between 15 and $35^{\circ} \mathrm{C}$ (Table 1). Percentage mortality was low to moderate $(<35 \%)$ between 15 and $30^{\circ} \mathrm{C}$ for constant temperatures and between 18 and $27^{\circ} \mathrm{C}$ for variable temperatures. The only exception was the high egg mortality at $27^{\circ} \mathrm{C}$ at constant temperature, possibly because of some kind of uncontrolled methodological problems or egg contamination. The temperature-dependent mortality values increase rapidly at both higher and lower temperatures outside these intervals, with a sharper increase for lower than for higher temperatures. The observed mortality of $\approx 2 \%$ at $15^{\circ} \mathrm{C}$ under constant temperatures is much lower than that observed for the same mean under alternating temperatures $(38.94 \%)$. In the range of temperatures above $30^{\circ} \mathrm{C}$, the mortality rate is also greater under alternating than under constant temperatures. However, for the proposed variable temperature regimes, the minimal temperature that causes $100 \%$ of mortality has not been found. Survival was significantly different between temperature regimes $\left(\chi^{2}=79.10 ; \mathrm{df}=17 ; P=0.00\right)$. Thus, over the range of temperatures proposed in this work, mortality for this developmental stage fits a U-shaped pattern for constant temperatures whereas a J-shaped curve describes the mortality for variable temperatures.

The developmental time of the embryonic stage at constant temperatures decreases from almost $30 \mathrm{~d}$ at $15^{\circ} \mathrm{C}$ to little $>6 \mathrm{~d}$ at $32^{\circ} \mathrm{C}$ (Table 1 ). It decreases very sharply when the temperature increases from 15 to $21^{\circ} \mathrm{C}$, but the fall is much more gradual from 24 to $32^{\circ} \mathrm{C}$. From this temperature onwards, the developmental time increases up to $7.5 \mathrm{~d}$ at $35^{\circ} \mathrm{C}$. For variable temperatures, mean developmental time is never $<7 \mathrm{~d}$, showing the same behavior as that at constant temperatures, with a gradual decrease till $34^{\circ} \mathrm{C}$ and a later increase for greater temperatures. Nevertheless, mean developmental time at variable temperatures is greater than for constant temperatures in the interval assayed, except for at $18^{\circ} \mathrm{C}$. Statistically significant differences $(F=13,205.7$; $\mathrm{df}=17 ; P<0.001)$ between constant and alternating temperatures in $X$. arvicola egg development have been found.

Modeling Embryonic Developmental Rates. The parameter estimates, as well as the adjusted coefficients of determination are shown in Table 2 for the linear model and in Table 3 for the nonlinear models. The LT and UT were also calculated from the Logan type III and Lactin functions, whereas for the Briere model they are estimated parameters. Considering the characteristics of the linear model it is possible to determine the LT and the DD requirements for the egg development of this species (Table 2), but not the UT. The adjusted coefficients of determination for all nonlinear models were high for both constant and alternating temperatures $\left(\mathrm{R}_{\mathrm{a}}{ }^{2}>0.94\right)$ (Table 3$)$, indicating that these models can describe more of the variation in development rate than the linear model, whose adjustment was lower $\left(\mathrm{R}_{\mathrm{a}}{ }^{2}<0.82\right)$, especially for constant temperatures as expected.

Table 2. Parameter estimates and adjusted coefficients of determination for linear functions describing relationships between temp $\left({ }^{\circ} \mathrm{C}\right)$ and developmental rates $(1 / \mathrm{d})$ of embryonic stage for $X$. arvicola

\begin{tabular}{lccrcc}
\hline \multirow{2}{*}{\multicolumn{1}{c}{ Temp $^{a}$}} & \multicolumn{5}{c}{ Parameter estimates $^{b}$} \\
\cline { 2 - 6 } & \multicolumn{1}{c}{$a$} & $b$ & \multicolumn{1}{c}{$T_{0}$} & $D D$ & $\mathrm{R}_{\mathrm{a}}{ }^{2}$ \\
\hline Constant & -0.0334 & 0.00574 & 5.82 & 174.22 & 0.763 \\
Variable & -0.0240 & 0.00492 & 4.88 & 203.25 & 0.813 \\
Constant 15 to $27^{\circ} \mathrm{C}$ & -0.1090 & 0.00953 & 11.43 & 104.89 & 0.971 \\
Variable 15 to $27^{\circ} \mathrm{C}$ & -0.0778 & 0.00760 & 10.24 & 131.58 & 0.935
\end{tabular}

${ }^{a}$ Number of data points used in the estimation, $n=9$.

${ }^{b} a$, intercept; $b$, slope; $T_{0}$, estimated lower developmental threshold; $D D$, cumulative degree-days for development; $\mathbf{R}^{2}$, adjusted coefficient of determination between the developmental rate $(r=1 / \mathrm{d})$ and temp $\left({ }^{\circ} \mathrm{C}\right)$. 
Table 3. Parameter estimates and adjusted coefficients of determination for nonlinear Logan type III (Hilbert and Logan 1983 ), Lactin (Lactin et al. 1995), and Brière (Brière et al. 1999) functions describing relationships between temp $\left({ }^{\circ} \mathrm{C}\right)$ and developmental rates (1/d) of embryonic stage for $X$. arvicola

\begin{tabular}{|c|c|c|c|c|c|c|c|c|c|}
\hline Function & Temp $^{a}$ & & & ameter estim & & & LT & UT & $\mathrm{R}_{\mathrm{a}}^{2}$ \\
\hline \multirow[t]{3}{*}{ Logan type III } & & $\Psi$ & $D$ & $\Delta T$ & $T_{m}$ & $T_{b}$ & & & \\
\hline & Constant & 0.207 & 11.695 & 0.782 & 26.184 & 10.182 & 10.2 & 36.2 & 0.965 \\
\hline & Variable & 0.255 & 20.681 & 2.527 & 33.023 & 6.607 & 6.7 & 38.7 & 0.948 \\
\hline \multirow[t]{3}{*}{ Lactin } & & & $\rho$ & $\lambda$ & $T_{\max }$ & $\Delta$ & & & \\
\hline & Constant & & 0.00935 & -1.115 & 48.061 & 5.299 & 11.8 & 42.3 & 0.953 \\
\hline & Variable & & 0.00715 & -1.077 & 46.903 & 4.193 & 10.3 & 40.9 & 0.962 \\
\hline \multirow[t]{3}{*}{ Brire } & & & & $a$ & $T_{L}$ & $T_{o}$ & & & \\
\hline & Constant & & & 0.0000930 & 37.78 & 9.66 & 9.7 & 37.8 & 0.961 \\
\hline & Variable & & & 0.0000717 & 38.46 & 7.95 & 7.9 & 38.5 & 0.968 \\
\hline
\end{tabular}

${ }^{a}$ Number of data points used in the estimation, $n=9 . \mathrm{S}$.

${ }^{b} \Psi$ and $D$, empirical constants; $\Delta T$, width of high temp boundary area; $T_{m}$, lethal max temp threshold; $T_{b}$, base temp; $\rho$, acceleration of the function; $\lambda$, parameter that allows the curve to intersect the abscissa at suboptimal temperatures; $T_{\max }$, supraoptimal temp at which $r(T)=$ $\lambda ; \Delta$, range of temp between $T_{\max }$ and the temp at which $r(T)$ is max; $a$, empirical constant; $T_{L}$, estimated upper developmental threshold; $T_{o}$, estimated lower developmental threshold; LT, lower developmental threshold in ${ }^{\circ} \mathrm{C}$; UT, upper developmental threshold in ${ }^{\circ} \mathrm{C}$; $\mathrm{R}_{\mathrm{a}}{ }^{2}$, adjusted coefficient of determination.

The LT's obtained with the linear model (Table 2) were much lower than those obtained with the nonlinear models (Table 3), as a consequence of the reduction in the value of the linear model curve because of the values of the developmental rate at higher temperatures. The data from 15 to $27^{\circ} \mathrm{C}$ are not curved and can be treated as a straight line. The linear regression only on points that are not part of the curve produced $\mathrm{a} \mathrm{R}_{\mathrm{a}}{ }^{2}=0.97$ and $\mathrm{a} \mathrm{LT}$ of $11.43^{\circ} \mathrm{C}$ for constant temperatures and $\mathrm{a}_{\mathrm{a}}{ }^{2}=0.93$ and a $\mathrm{LT}$ of $10.24^{\circ} \mathrm{C}$ for variable temperatures, respectively (Table 2 ).

The LTs predicted by the nonlinear models were smaller for variable than for constant temperatures even though the differences in the estimates of these models for constant and variable temperatures were greater than with the linear models. The Lactin model is the one that offers the highest values for these estimates for both constant and alternating temperatures (Table 3). The optimum estimated temperatures of these models for the embryonic development rate (Fig. 2) were $32.9^{\circ} \mathrm{C}$ in the Logan type III model, $31.3^{\circ} \mathrm{C}$ in the Lactin model and $31.4^{\circ} \mathrm{C}$ in the Brière model for constant temperatures, while for variable temperature regimes the values were $31.9 ; 31.8$ and $31.7^{\circ} \mathrm{C}$, respectively. These are the temperatures from which the development rates decrease and in both cases the Logan type III model shows the highest values. The UTs for each model were higher for variable temperatures except for the Lactin model that showed greater values for constant temperature regimes and that showed the greatest values again $(\mathrm{Ta}-$ ble 3).

The patterns exhibited by the nonlinear models were very similar for all of them (Fig. 2), showing a sudden decrease in the development rate from the predicted optimum temperature until the UT is reached, whereas for temperatures close to the LT the curves approach zero asymptotically. The development rate function between 18 and $27^{\circ} \mathrm{C}$ fits a straight line well.

Validating the Models Under Field Conditions. Table 4 shows the duration of egg development obtained under field conditions and the values estimated by the different models under constant and alternating temperature regimes. Egg survival under field conditions was $94.3 \%$, and mean developmental time $15.85 \mathrm{~d}$. The fit of the models to the field development was calculated by dividing the developmental time predicted by each model by the mean field developmental time. The fits were better for nonlinear models than for the linear model at both constant and variable temperatures. The fits were better for variable temperatures, except for the Logan type III model, in which the fit, although very similar, is better for constant temperatures. The Lactin model offers the best fit for variable temperatures $(99.18 \%)$ and the worst fit $(91.36 \%)$ for constant temperatures, respectively.

The linear model predicted a faster development than what really happens in the field (around a 12\% for constant temperatures and a 7\% for alternating) and the nonlinear models predicted a development between 9 and $1.5 \%$ faster for constant temperatures and between 1 and $2 \%$ slower for variable temperatures.

\section{Discussion}

The influence of the temperature and its variation on the embryonic development of coleopteran species is well documented (Hagstrum and Milliken 1991, Marco et al. 1997, Zilahi-Balogh et al. 2003). This work has demonstrated that the eggs of $X$. arvicola could complete their development between 15 and $35^{\circ} \mathrm{C}$. These temperatures occur in northern Spain during late spring and summer (from March to July), coinciding with adult emergence and egg laying for this species in the field (Moreno 2005), showing that, among other factors, the eggs seem to be well adapted to those temperature regimes. Keena (2006) studied the effect of temperature in different life cycle parameters of another cerambycid, Anoplophora glabripennis Motschulsky, established in the laboratory from infestations in Illinois and New York, obtaining similar critical egg survivorship temperature thresholds (12 and $34^{\circ} \mathrm{C}$, respectively) to those observed for X. arvicola in this work. 
Constant Temperatures
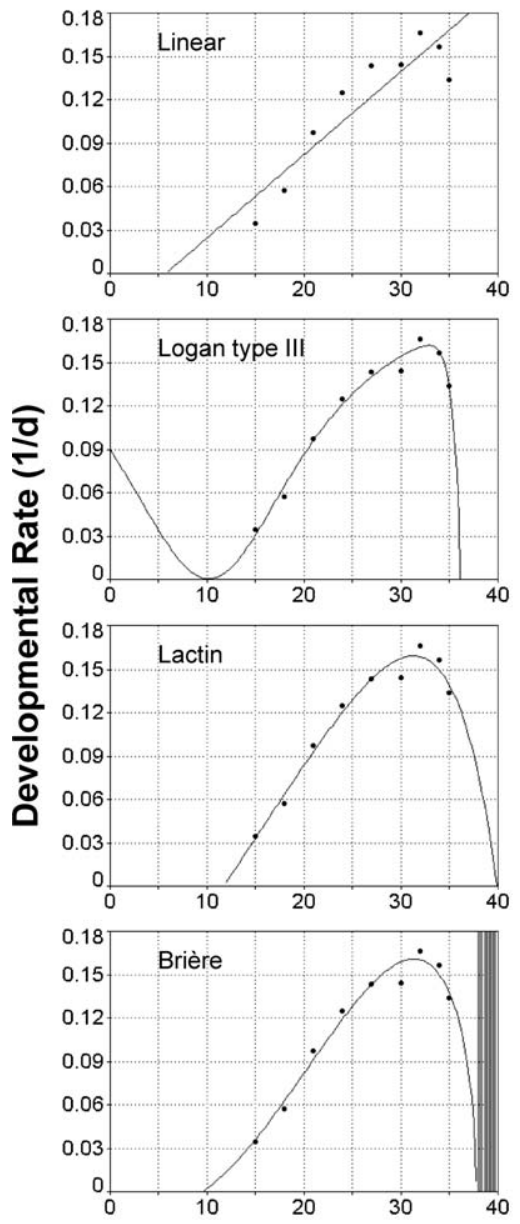

Variable Temperatures
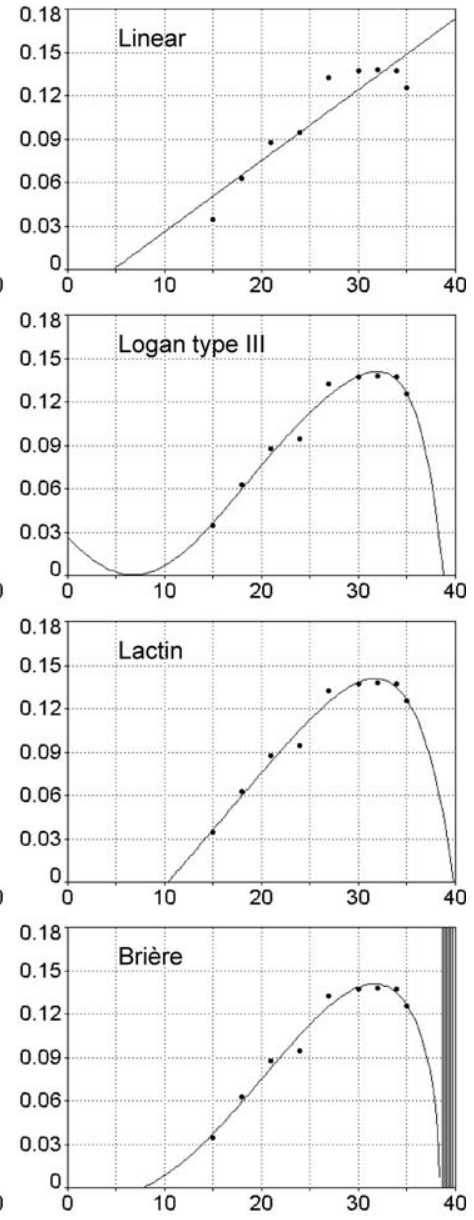

Temperature $\left({ }^{\circ} \mathrm{C}\right)$

Fig. 2. Predicted rate of embryonic development (1/d) of $X$. arvicola as a function of constant and variable temperatures $\left({ }^{\circ} \mathrm{C}\right)$ by Linear, Logan type III, Lactin and Briére models. $(\bullet)$ : Observed developmental rate. (-): Line of best fit.

The range of temperatures at which a certain developmental stage shows low mortality is intrinsic to the species ( $\mathrm{Li} \mathrm{1995)}$, and for every insect stage the curve that relates the mortality with the temperature has a U shape, with low and practically constant mortalities in the range of favorable temperatures and with a high percentage of mortality beyond some critical maximum or minimum temperatures (Smith and Ward 1995). According to this, the eggs of X. arvicola showed low mortality for the range of constant temperatures between 15 and $30^{\circ} \mathrm{C}$ that increased sharply at both ends of this range, reaching $100 \%$ mortality for temperatures at 12 and $36^{\circ} \mathrm{C}$. However, the range of alternating favorable temperatures was narrower (between 18 and $27^{\circ} \mathrm{C}$ ). For 15 and $30^{\circ} \mathrm{C}$ alternating temperature regimes, part of the cycle occurs at 12 and $36^{\circ} \mathrm{C}$, respectively, temperatures at which no egg survivorship was observed for the corresponding constant regimes. This could explain the increase in egg mortality for those variable temperatures, because it has been reported by other authors that eggs of different species presented lower percent hatching after exposure to temperatures under the critical minimum or over the critical maximum (Lin et al. 1954, Liu et al. 2002).

Campbell et al. (1974) stated that development rate under variable temperatures should not significantly differ from that observed with constant temperature regimes. Nevertheless, many other authors suggest that the presence of daily temperature cycles plays an important role in the development of many insect species (Fornasari 1995). In fact, Hagstrum and Milliken (1991) cited 10 coleopteran species and up to 63 species from other families in which the variation of temperature within a day had a marked effect on the duration of development. Howe (1967) pointed out that if varying temperature was represented by a temperature mean, insect eggs hatched before expected for the lower temperatures of the range, approximately in the ex- 
Table 4. Days necessary for the embryonic development of $X$. arvicola under field conditions and the estimates of the models for constant and alternating temperatures by integration of the increments in development at 30-min intervals within the lower and upper developmental temp limits given by each model and the percentage of fit of developmental times predicted by each model in relation to field developmental time

\begin{tabular}{llcc}
\hline \hline & Temp & $\begin{array}{c}\text { Developmental } \\
\text { time }(\mathrm{d})\end{array}$ & $\begin{array}{c}\% \\
\text { Adjust }\end{array}$ \\
\hline Model & & & \\
Linear & Constant & 13.88 & 87.55 \\
Logan type III & Variable & 14.69 & 92.67 \\
& Constant & 15.65 & 98.73 \\
Lactin & Variable & 16.17 & 97.98 \\
& Constant & 14.48 & 91.36 \\
\multirow{2}{*}{ Brière } & Variable & 15.98 & 99.18 \\
& Constant & 15.08 & 95.17 \\
Field & Variable & 16.04 & 98.79 \\
\hline
\end{tabular}

pected time in the intermediate range, and with some delay for the upper temperatures of the range. Our results agree partially to this hypothesis, because under variable temperature regimes the embryonic development of $X$. arvicola was significantly slower for temperatures over $21^{\circ} \mathrm{C}$ and faster at $18^{\circ} \mathrm{C}$, than those obtained under constant temperatures. However, no significant differences were observed at the higher $\left(35^{\circ} \mathrm{C}\right)$ and lower $\left(15^{\circ} \mathrm{C}\right)$ variable temperatures tested. Therefore, the differences in developmental rates between constant and alternating temperatures with the same mean seem to be more dependent on the temperature fluctuation amplitude around this mean than on the temperature itself

The estimated LT was smaller for alternating than for constant temperatures for the different models used $\left(0.9,1.5,1.7\right.$, and $3.5^{\circ} \mathrm{C}$ for linear regression and the Lactin, Brière, and Logan type III nonlinear models, respectively). According to Richards and Suanraksa (1962), the energy obtained at temperatures greater than the LT made possible the development at alternating temperatures during the periods in which the temperature was lower than this critical point. The estimated UTs also depend on the temperature regime used, the Lactin model predicting a $1.4^{\circ} \mathrm{C}$ drop in this parameter under variable temperatures with respect to the constant one, while the Logan type III and Brière models predicted an increase of 2.5 and $0.7^{\circ} \mathrm{C}$, respectively. Nevertheless, all the estimated values for the UT (between $36.2^{\circ} \mathrm{C}$ for Logan type III and $42.3^{\circ} \mathrm{C}$ for Lactin, both at constant temperatures) were greater than the highest temperature at which egg survival was observed $\left(35^{\circ} \mathrm{C}\right)$, and together with the high variability depending on the model indicate that this parameter needs a more exhaustive study. The optimal embryonic developmental temperature was estimated to be between 30 and $32^{\circ} \mathrm{C}$ depending on the model, and this value is similar for both constant and alternating temperatures. Messenger and Flitters (1959) obtained values of UT, LT and optimal temperature under alternating temperatures $5^{\circ} \mathrm{C}$ lower than those observed with constant temperatures.
However, Johnson (1940) found that a daily alternation of temperature with a range of $10^{\circ} \mathrm{C}$ between the threshold and optimum constant temperatures resulted in an acceleration of the embryonic development, indicating a possible higher variable temperature optimum, as also observed by Mironidis and Savopoulou-Soultani (2008) with an almost $5^{\circ} \mathrm{C}$ higher temperature optimum at alternating than at constant temperature regimes.

The field validation confirmed a better prediction with the Lactin model, followed by the Brière model, both constructed with variable temperature regimes, with a development prediction adjustment error of a few hours. The three nonlinear models adjusted with constant temperatures predicted developmental times shorter than measured under field conditions, whereas at alternating temperatures the predicted developmental times were higher than observed. This result may be considered unexpected, because, with the exception of the Lactin model, the estimated lower and higher thresholds with alternating temperatures differed more widely between each other than with constant temperatures and consequently the predicted development with alternating temperatures should be shorter. However, the highest temperature measured during the field validation $\left(35.9^{\circ} \mathrm{C}\right)$ does not reach the upper developmental thresholds estimated with the nonlinear models. In addition, developmental rates for constant temperatures over $21^{\circ} \mathrm{C}$ were higher than for variable temperatures and, considering that developmental time is more dependent on the higher than on the lower temperatures (Howe 1967, Hagstrum and Milliken 1991), the models constructed with constant temperatures predicted faster developments than those predicted by the models with alternating temperatures and even faster than development observed in the field.

Linear models of development continue to be widely used for predictions in the practice because their parameters are easily estimated from developmental data and often yield the desired accuracy (Fan et al. 1992). In this case, the small value of the LT and the lack of UT, result in the worst prediction, with a shortening of the predicted developmental time with respect to field data ( $12 \%$ for constant and $7 \%$ for variable temperatures), and consequently the linear model does not appear to be reliable enough to predict what happens in natural conditions. Considering only developmental rate within the straight part of the curve (from 15 to $27^{\circ} \mathrm{C}$ ) and ignoring the development data above $27^{\circ} \mathrm{C}$ would lead to invalidate the measures made at different temperatures, which are more important to estimate thermal developmental thresholds.

The prediction of $X$. arvicola embryonic development together with the corresponding predictions for the other development stages can provide the biological basis to support an effective integrated management program of this pest. Future research should use the nonlinear models because they provide a better fit of the data and should take into account the differences observed between con- 
stant and alternating temperatures, as the latter are more similar to those the species experiences in grape vineyards.

\section{Acknowledgments}

We are thankful to F. Ortego for his critical review of the manuscript. The Spanish Institute for Food and Agricultural Sciences and Technologies (INIA) funded this research, project no. RTA04-117-C2.

\section{References Cited}

Adachi, I. 1988. Reproductive biology of the white-spotted longicorn beetle, Anoplophora malasiaca Thomson (Coleoptera: Cerambycidae), in citrus trees. Appl. Entomol. Zool. 23: 256-264.

Beck, S. D. 1983. Insect thermoperiodism. Annu. Rev. Entomol. 28: 91-108.

Behrens, W., K. Hoffmann, S. Kempa, S. Gabler, and G. Merkel. 1983. Effects of diurnal thermoperiods and quickly oscillating temperatures on the development and reproduction of crickets, Gryllus bimaculatus. Oecologia 59: 279-287.

Brière, J. F., P. Pracros, A. Y. Le Roux, and J. S. Pierre. 1999. A novel model of temperature-dependent development for arthropods. Environ. Entomol. 28: 22-29.

Campbell, A., B. D. Frazer, N. Gilbert, A. P. Gutierrez, and M. Mackauker. 1974. Temperature requirements of some aphids and their parasites. J. Appl. Ecol. 11: 431-438.

Fan, Y., E. Groden, and F. A. Drummond. 1992. Temperature-dependent development of Mexican bean beetle (Coleoptera: Coccinellidae) under constant and variable temperatures. J. Econ. Entomol. 85: 1762-1770.

Fornasari, L. 1995. Temperature effects on the embryonic development of Aphthona abdominalis (Coleoptera: Chrysomelidae), a natural enemy of Euphorbia esula (Euphorbiales: Euphorbiaceae). Environ. Entomol. 24: $720-$ 723.

Hagstrum, D. W., and G. A. Milliken. 1991. Modeling differences in insect developmental times between constant and fluctuating temperatures. Ann. Entomol. Soc. Am. 84: 369-379.

Hilbert, D. W., and J. A. Logan. 1983. Empirical model of nymphal development for the migratory grasshopper, Melanopus sanguinipes (Orthoptera, Acrididae). Environ. Entomol. 12: 1-5.

Howe, R. W. 1967. Temperature effect on embryonic development in insects. Annu. Rev. Entomol. 12: 15-41.

Jandel Scientific. 1994. TableCurve user's manual. Jandel Scientific, San Rafael, CA.

Johnson, C. G. 1940. Development, hatching and mortality of the eggs of Cimex lectularius in relation to climate, with observations on the effects of pre-conditioning to temperature. Parasitology 32: 127-173.

Keena, M. A. 2006. Effects of temperature on Anoplophora glabripennis (Coleoptera: Cerambycidae) adult survival, reproduction and egg hatch. Environ. Entomol. 35: 912921.

Lactin, D. J., N. J. Holliday, D. L. Johnson, and R. Craigen. 1995. An improved rate model of temperature-dependent development by arthropods. Environ. Entomol. 24: $68-75$.

Li, D. 1995. Development and survival of Eriginidium graminicolum (Sundevall) (Aranea: Lyniphiidae: Erigoninae) at constant temperature. Bull. Entomol. Res. 85: 79-91.
Lin, S., A. C. Hodson, and A. G. Richards. 1954. An analysis of threshold temperatures for the development of Oncopeltus and Tribolium eggs. Physiol. Zool. 27: 287-311.

Liu, S. S., F. Z. Chen, and M. P. Zalucki. 2002. Development and survival of the diamondback moth (Lepidoptera: Plutellidae) at constant and alternating temperatures. Environ. Entomol. 31: 221-231.

Logan, J. A. 1988. Toward an expert system for development of pest simulation models. Environ. Entomol. 17: 359-376.

Logan, J. A., D. J. Wollkind, S. C. Hoyt, and L. K. Tanigoshi. 1976. An analytic model for description of temperature dependent rate phenomena in arthropods. Environ. Entomol. 5: 1133-1140.

Marco, V., A. Taberner, and P. Castañera. 1997. Development and survival of immature Aubeonymus mariaefranciscae (Coleoptera: Curculionidae) at constant temperatures. Ann. Entomol. Soc. Am. 90: 169-176.

Messenger, P. S., and N. E. Flitters. 1959. Effect of variable environments on egg development of three species of fruit flies. Ann. Entomol. Soc. Am. 52: 191-204.

Mironidis, G. K., and M. Savopoulou-Soultani. 2008. Development, survivorship, and reproduction of Helicoverpa armigera (Lepidoptera: Noctuidae) under constant and alternating temperatures. Environ. Entomol. 37: 16-28.

Moreno, C. M. 2005. Xylotrechus arvicola (Olivier, 1795) (Coleoptera: Cerambycidae): descripción morfológica, ciclo biológico, incidencia y daños en el cultivo de la vid. ITACYL Publications, Valladolid, Spain.

Ocete, R., and R. Del Tío. 1996. Presencia del perforador Xylotrechus arvicola (Olivier) (Coleoptera, Cerambycidae) en viñedos de la Rioja Alta. Bol. San. Veg. Plagas. 22: 199-202.

Ocete, R., M. A. López-Martínez, C. Prendes, C. D. Lorenzo, J. L. González-Andújar, and M. Lara. 2002. Xylotrechus arvicola (Olivier) (Coleoptera: Cerambycidae), a new impacting pest on Spanish vineyards. Vitis 41: 211-212.

Ratte,H. T. 1985. Temperature and insect development. pp. 33-66. In K. H. Hoffmann (ed.), Environmental physiology and biochemistry of insects. Springer, Berlin, Germany.

Richards, A. G., and S. Suanraksa. 1962. Energy expenditure during embryonic development under constant and variable temperatures (Oncopeltus fasciatus). Entomol. Exp. Appl. 5: 167-178.

Rodríguez, M., P. J. Ocaña, and M. Oliver. 1997. Presencia del perforador Xylotrechus arvicola (Olivier) en viñas de la provincia de Ciudad Real. In Proceedings, 22th Reunión del Grupo de Trabajo de los Problemas Fitosanitarios de la Vid, 18-20 February 1997. Ciudad Real, Spain.

SAS Institute. 2003. PROC user's manual, version 9.1. SAS Institute, Cary, NC.

Sharpe, P.J.H., and D. W. DeMichele. 1977. Reaction kinetics of poikilotherm development. J. Theor. Biol. 64: 649670.

Smith, A. M., and S. Ward. 1995. Temperature effects on larval and pupal development, adult emergence, and survival of the pea weevil (Coleoptera: Chrysomelidae). Environ. Entomol. 24: 623-634.

Sokal, R. R., and F. J. Rohlf. 1995. Biometry, 3rd ed. Freeman, New York.

Toapanta, M. A., D. J. Schuster, and P. A. Stansly. 2005. Development and life history of Anthonomus eugenii (Coleoptera: Curculionidae) at constant temperatures. Environ. Entomol. 34: 999-1008.

Villiers, A. 1978. Faune des Coléoptères de France. I. Cerambycidae. Encyclopédie Entomologique XLII. Lechevalier, Paris, France. 
Wagner, T. L., H. Wu, P.J.H. Sharpe, R. M. Schooldfield, and R. N. Coulson. 1984. Modelling insect development rates: a literature review and application of a biophysical model. Ann. Entomol. Soc. Am. 77: 208-225.

Weston, P. A., and M. D. Díaz. 2005. Thermal requirements and development of immature stages of Viburnum leaf beetle, Pyrrhalta viburni (Paykull) (Coleoptera: Chrysomelidae). Environ. Entomol. 34: 985-989.

Worner, S. P. 1992. Performance of phenological models under variable temperature regimes: consequences of the
Kaufmann or rate summation effect. Environ. Entomol. 21: 689-699.

Zilahi-Balogh, G. M., S. M. Salom, and L. T. Kok. 2003. Temperature-dependent development of the specialist predator Laricobius nigrinus Fender (Coleoptera: Derodontidae). Environ. Entomol. 32: 1322-1328.

Received 18 March 2011; accepted 27 May 2011. 